\title{
Point in Time Test Given
}

National Cancer Institute

\section{Source}

National Cancer Institute. Point in Time Test Given. NCI Thesaurus. Code C81297.

The hour, minute, and/or second that an examination was administered. 